\title{
Reconstructing and analyzing China's fifty-nine year (1951-2009) drought history using hydrological model simulation
}

\author{
Z. Y. Wu ${ }^{1,2}$, G. H. Lu ${ }^{1}$, L. Wen ${ }^{3}$, and C. A. Lin $^{4}$ \\ ${ }^{1}$ State Key Laboratory of Hydrology-Water Resources and Hydraulic Engineering, Hohai University, Nanjing, China \\ ${ }^{2}$ College of Hydrology and Water Resources, Hohai University, Nanjing, China \\ ${ }^{3}$ Department of Atmospheric and Oceanic Sciences, and Global Environmental and Climate Change Centre, \\ McGill University, Montréal, Canada \\ ${ }^{4}$ Atmospheric Science and Technology Directorate, Environment Canada, Montréal, Canada
}

Received: 27 January 2011 - Published in Hydrol. Earth Syst. Sci. Discuss.: 10 February 2011

Revised: 7 July 2011 - Accepted: 16 August 2011 - Published: 15 September 2011

\begin{abstract}
The 1951-2009 drought history of China is reconstructed using daily soil moisture values generated by the Variable Infiltration Capacity (VIC) land surface macroscale hydrology model. VIC is applied over a grid of 10458 points with a spatial resolution of $30 \mathrm{~km} \times 30 \mathrm{~km}$, and is driven by observed daily maximum and minimum air temperature and precipitation from 624 long-term meteorological stations. The VIC soil moisture is used to calculate the Soil Moisture Anomaly Percentage Index (SMAPI), which can be used as a measure of the severity of agricultural drought on a global basis. We have developed a SMAPI-based drought identification procedure for practical uses in the identification of both grid point and regional drought events. As a result, a total of 325 regional drought events varying in time and strength are identified from China's nine drought study regions. These drought events can thus be assessed quantitatively at different spatial and temporal scales. The result shows that the severe drought events of 1978, 2000 and 2006 are well reconstructed, which indicates that the SMAPI is capable of identifying the onset of a drought event, its progression, as well as its termination. Spatial and temporal variations of droughts in China's nine drought study regions are studied. Our result shows that on average, up to $30 \%$ of the total area of China is prone to drought. Regionally, an upward trend in drought-affected areas has been detected in three regions (Inner Mongolia, Northeast and North) from 1951-2009. However, the decadal variability of droughts has been weak in the rest of the five regions (South, Southwest,
\end{abstract}

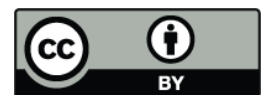

Correspondence to: $\mathrm{Z}$. Y. Wu

(wzyhhu@gmail.com)
East, Northwest, and Tibet). Xinjiang has even been showing steadily wetter since the 1950s. Two regional dry centres are discovered in China as the result of a combined analysis on the occurrence of drought events from both grid points and drought study regions. The first centre is located in the area partially covered by the North and the Northwest, which extends to the southeastern portion of Inner Mongolia and the southwest part of Northeast. The second one is found on the central to southern portion of the South. Our study demonstrates the applicability and the value of using modeled soil moisture for reconstructing drought histories, and the SMAPI is useful for analyzing drought at different spatial and temporal scales.

\section{Introduction}

Drought is one of the major natural disasters that human beings have been suffering since the ancient era. Even today with well developed science and technology, drought is still considered as the most serious hazard to agricultural productivity and human lives worldwide. Frequently occurring drought events in recent decades have become major environmental and climatic challenges in the new millennium. With rapid expansion of the world population and socio-economic development, there is an increasing emphasis on the issue of water shortage. With such a shortage of water, the existing drought-affected areas could be further extended. The drought severity would be aggravated too. These will certainly cast a shadow on future socio-economic development,

Published by Copernicus Publications on behalf of the European Geosciences Union. 
which will consequently threaten the well-being of nations and the environment.

Since the greatest part of continental China is located in the monsoon climate zone, the monthly, annual and interannual variations in precipitation and temperature are significant. Thus, large-scale droughts often occur in China. The historical record of droughts shows that China was hit with 1056 major drought events during the period between $206 \mathrm{BC}-1949$ AD (or in $2155 \mathrm{yr}$ ), or it has had one major drought every two years. (Chinese Ministry of Water Resources; CMWR, 1997). The drought situation in China has been worsening since the 1950s. The annual average of drought-affected areas has reached 22.5 million hectares, which can account for up to $60 \%$ of the total areas that suffered from natural disasters in China. The annual average of grain yields lost to droughts is about 12.8 billion kilograms (Zhang, 2003), which would be enough to feed 85 million people annually. China's drought situation has further deteriorated since the 1990s. Nationwide droughts occur almost every year (Zou et al., 2005; Zhai et al., 2010; Ma and Ren, 2007; Dai et al., 2004), causing more and more grain yield losses and even threatening the security of drinking water supplies. Drought disasters have become a key factor constraining the sustainable socio-economic development. Therefore, conducting drought researches and innovating new methodologies to reconstructing historical drought events would enhance our knowledge on drought characteristics, thus contributing to drought monitoring and prediction.

The popular idea for drought reconstruction is the use of a drought index that can measure the severity of droughts. Because of the complexity of drought and its causing factors, most drought indices are based on specific geographical and time range (Richard and Heim, 2002), resulting in hundreds of drought indices for applications around the world (World Meteorological Organization; WMO, 1975; Heim, 2000). Most of these indices are precipitation-based only, as drought is directly caused by the shortage of rainfall, and precipitation data is easier to obtain than other atmospheric variables (e.g. Raziei et al., 2008). For example, the Palmer Drought Severity Index (PDSI; Palmer, 1965) and the Standardized Precipitation Index (SPI; McKee et al., 1993) are two commonly used indices of meteorological drought worldwide (e.g. Bordi et al., 2009; Vicente-Serrano and López-Moreno, 2005). Zou et al. (2005) used PDSI to investigate the variations in droughts over China, and Zhai et al. (2010) used both PDSI and SPI to identify tendencies in dry and wet conditions during recent decades over 10 large regions in China. However, Zhai et al. (2010) found that many basins' droughts were caused not only by lower precipitation but also by other factors influencing water balance conditions. In fact, for agriculture, the first sector to be affected by the onset of droughts (Narasimhan and Srinivasan, 2005), soil moisture, is more crucial than precipitation. Sufficient water supply is essential for the growth of crops at different stages. The crop production is thus strongly influenced by soil moisture condi- tions. According to WMO (1975), the agriculture drought relates to a shortage of available water for plant growth, and is assessed as insufficient soil moisture to replace evapotranspirative losses. Having accurate soil moisture information is thus essential and important for assessing and predicting agricultural droughts.

It is not easy to obtain soil moisture measurements from field surveys on large scales. Soil moisture often exhibits a strong spatial and temporal heterogeneity at small scales, which further complicates interpretation of observations. Soil moisture can vary significantly among different in situ measurements even within a small area (Bergman et al., 1988). This is mainly due to irregular inputs of water to the soil column from variations in snow accumulation or runoff, and redistribution of soil water along hill slope gradients; these factors vary with soil, vegetation, and topographic characteristics (Gray, 1970). There is no consistent soil moisture monitoring networks that can provide long datasets of soil moisture conditions in China. According to Zuo and Zhang (2008), there are only 279 sites providing in situ soil moisture measurements in China. They are unevenly distributed in the country and concentrated in the regions of Northeast, North and Huaihe. Among those sites, only 61 have a data series more than $20 \mathrm{yr}$. Remote sensing is an alternative to in situ measurements at large scales, but the current remote sensing techniques can only give soil water content in top thin layers and the data records are very short (Albergel et al., 2010; Juglea et al., 2010; Lievens et al., 2011; Loew and Schlenz, 2011). Having a long dataset of large-scale soil moistures would be essential for systematically studying the history of agricultural drought and its trend over a large area in a long period of time.

Recent advances in the development of macroscale land surface hydrological models offer the potential to reconstruct and continually update spatial and temporal distribution of soil moisture over a large area (Wu et al., 2007). The simulated soil moisture has been used in many drought studies (Andreadis et al., 2005; Sheffield et al., 2004; Mo, 2008). Such an approach has three advantages. Firstly, those hydrological models are able to realistically reflect soil moisture states, as considering the different vegetation types and soil characteristics on the impact of hydrological processes. Secondly, the models can achieve an ideal regional average of soil moistures to better reflect the consolidation of the region through regional energy and water balance calculation, and this could reduce the uncertainty induced by interpolation using only observations. Thirdly, such models can also simulate the daily soil moisture to facilitate the establishment of a daily drought index. The hydrological modelbased soil moisture approach is thus suitable for analyzing the drought occurrence and intensity at different spatial and temporal scales.

The VIC (Variable Infiltration Capacity) model (Liang et al., 1994, 1996) is a land surface macroscale hydrology model that has been widely used in different parts of the 
world (Lobmeyr et al., 1999; te Linde et al., 2008; Stephen et al., 2010). It uses a spatial probability distribution function to represent subgrid variability in soil moisture storage capacity. Such a function is used in Xinanjiang model (Zhao et al., 1980), Hamburg Climate Model (Dümenil and Todini, 1992), Interface Soil Biosphere Atmosphere model (Habets et al., 1999), and Canadian Land Surface Scheme (CLASS; Verseghy, 1991; Verseghy et al., 1993; Wen et al., 2007) for calculating saturation excess runoff, and the General Runoff Yield model (Wen et al., 1982) for generating infiltration excess runoff. The function is designed to take into account the heterogeneity of land surface properties, and can give a more realistic treatment of hydrological processes within a model grid cell. Nijssen et al. (2001) used VIC to generate $14 \mathrm{yr}$ (1980-1993) of global daily soil moisture at a resolution of $2^{\circ} \times 2^{\circ}$. Andreadis et al. (2005) reconstructed the drought history of the continental US from 1920 to 2003 based upon VIC soil moisture and runoff at a resolution of $0.5^{\circ} \times 0.5^{\circ}$. Wu et al. (2007) applied VIC to generate $35 \mathrm{yr}$ (1971-2005) of daily soil moisture over China at a resolution of $30 \mathrm{~km} \times 30 \mathrm{~km}$. Wen et al. (2011) recently used VIC to reconstruct $60 \mathrm{yr}$ daily soil moisture over the Canadian Prairies.

The soil moisture dataset used in this study is derived from a newly-completed multiyear VIC simulation, which extends the simulation period from previous thirty-five years (19712005; Wu et al., 2007) to current fifty-nine years (19512009). Thus, our current study is a continuation of the study of Wu et al. (2007), with the emphasis on the analysis and application of the long-term VIC soil moisture simulation. The VIC moisture is used to calculate the Soil Moisture Anomaly Percentage Index (SMAPI; Bergman et al., 1988), which can be used as a measure of the severity of agricultural droughts. The details of the SMAPI will be discussed in a later section. The calculated SMAPI is ultimately used to quantify the most documented drought events from 1951-2009 in China.

\section{Data and methodology}

\subsection{VIC soil moisture simulation}

Technically speaking, VIC is applied over a grid of 10458 points with a spatial resolution of $30 \mathrm{~km} \times 30 \mathrm{~km}$, which covers all 31 provinces in mainland China. VIC has four types of user-defined parameters: soil, vegetation, hydrology, and "catchment definition". By the latter, we mean basin characteristics (latitude, longitude, elevation) and climate parameters (time average near-surface air temperature and precipitation). For each grid point, the global $10-\mathrm{km}$ soil profile dataset (Reynolds et al., 2000) and the global 1-km land cover classification dataset (Hansen et al., 2000) are used to define the model soil and vegetation parameters. The catchment parameters of VIC are determined using the Global 30 Arc-Second Elevation Data Set from the US Geological Survey, and the observed time average near-surface air tempera- tures and precipitation archived at the China Meteorological Administration. Three soil layers are used in the model simulation with the top layer being fixed at $0.1 \mathrm{~m}$ depth. The depths of the second and third layer are adjustable, which are determined by the model calibration process. The regression relations between the VIC hydrological parameters and the catchment climate characteristics are used for the parameter determination over ungauged catchments, which are detailed in Wu et al. (2007).

VIC is driven by observed daily maximum and minimum air temperature and precipitation from 624 long-term meteorological stations in China. This continually updated meteorological dataset has been available since 1 January 1951 and is quality-controlled. The daily meteorological observations are interpolated onto each of the 10458 grid points using the inverse distance weighted method. VIC is then applied on each grid point for the calculation of surface water balance using a daily time step. The energy balance is not considered as long-term and nationwide observations of shortwave radiation are not available. The climatology of 1 January soil moisture from 1951-2009 is used as the initial soil moisture value for VIC to generate the soil moisture dataset.

VIC is first calibrated using observed hydrographs from 35 catchments with drainage areas varying from 190 to $351530 \mathrm{~km}^{2}$. The VIC model is then validated over these 35 catchments at different periods and over an additional eight catchments with drainage areas ranging from 1230 to $10010 \mathrm{~km}^{2}$. The calibration period varies from 5 to $6 \mathrm{yr}$, while the model validation is done using 2- to 7-yr observed hydrographs outside the calibration period. In situ soil moisture measurements from 28 sites around China are also used for model validation. VIC performs well over both calibration and validation catchments especially in humid and semihumid regions, and detailed VIC calibration and validation are discussed and provided in Wu et al. (2007). For example, the overall average values of correlation coefficient of simulated and observed soil moisture anomalies for the 28 sites are $0.60,0.50$ and 0.52 for depths of $0-20,20-100$ and $0-100 \mathrm{~cm}$ respectively, indicating satisfactory model performance on soil moisture simulation. Also, the 59-yr soil moisture climatology for the top $1 \mathrm{~m}$ from VIC is consistent with the known soil moisture conditions in China, illustrating the ability of the VIC model in reproducing large spatial scale characteristics of soil moisture over a long period of time.

\subsection{Soil moisture anomaly percentage index (SMAPI)}

The precise quantification of a drought event is a classical issue and difficult challenge in geosciences. Several specialized drought indices have been proposed to describe four major types of drought: meteorological, hydrological, agricultural and socio-economic (Heim, 2000). Agricultural drought refers to the phenomenon that the moisture supply falls below the climatically appropriate moisture supply so that the growth of crops is hindered, which may also include 
crop drought and soil drought. Four drought indices are commonly used in the agricultural sector. These indices are the crop moisture index (CMI; Palmer, 1968), the crop drought index (CDI), the soil moisture index (SMI), and the soil moisture anomaly percentage index (SMAPI). CMI is defined as the sum of evapotranspiration deficit and soil demand, being a by-product of PDSI. The model assumes that parameters like vegetation, soil properties, land use/cover are evenly distributed in the whole climatic zone, which varies widely in reality. CDI is built according to crops' physiological and ecological responds to drought by monitoring changes of crop growth, leaf temperature and leaf moisture to determine the effect of drought. Such an index is mainly based on satellite remote sensing measurement with short time series; it has as well a certain regional limitation. SMI is defined as the percentage of actual soil moisture accounted for the field capacity, reflecting the relatively dryness of soil. CMI can evaluate short-term moisture conditions affecting crops, while its rapid reaction to short-term changing information may mislead long-term changing information. Both CDI and SMI are suitable for monitoring small and special areas with particular soil types, crops and vegetative periods.

Different from the above three indices, the SMAPI has been developed to characterize agricultural drought over a large area. The SMAPI approach for defining a drought severity is through a measurement of the relative departure of soil moisture from the normal climate at a specific gird point or region. When the current soil moisture is less than the climatology soil moisture, the soil moisture deficit appears to identify the drought phenomenon. The rationale of using the relative soil moisture deficit rather than the absolute magnitude is because anomalies in absolute terms reflect different severities in different parts of a studying domain. Therefore, the dimensionality of the SMAPI makes it possible to compare drought severities at disparate grid points and regions in different periods, being available to characterize agricultural drought over a large area. In this study, the SMAPI is defined as:

SMAPI $=\frac{\theta-\bar{\theta}}{\bar{\theta}} \times 100 \%$

where, $\theta$ and $\bar{\theta}$ represent the current value of soil moisture and its climatology respectively. The climatically appropriate moisture should be the value that is based on the multiyear average in the same time series. Thus, the variable $\bar{\theta}$ in Eq. (1) can be seen as the mathematical expectation of a soil moisture time series.

Bergman et al. (1988) reported that the SMAPI values change at a rate centred between the rapid CMI and the relatively slow Palmer Drought Severity Index (PDSI; Palmer, 1965), which may both reflect the development of short-term drought and analyse the change of long-term drought. A useful survey on drought indices is found in WMO (1975) and Heim (2000). Keyantash and Dracup (2002) evaluated the most prominent indices that measure each of the three physi-

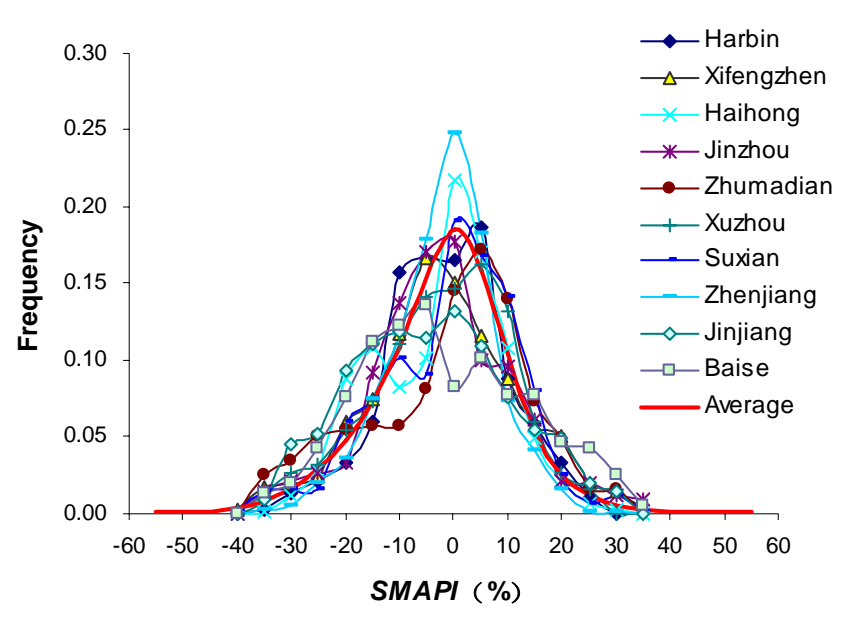

Fig. 1. The frequency distributions of the SMAPI (Soil Moisture Anomaly Percentage Index; see text for discussion) for 10 Chinese experimental sites together with their average.

cal types of drought (meteorological, hydrological, and agricultural) using a set of six weighted decision criteria: robustness, tractability, transparency, sophistication, expendability, and dimensionality. The performance of each of the 14 evaluated drought indices is measured with an assigned value from 1 to 5 ( 5 being the highest). The average value of the six criteria is 3 for the Soil Moisture Anomaly Percentage Index (SMAPI) proposed by Bergman et al. (1988), which is second highest among the five evaluated indices for agricultural drought. Thus, the SMAPI approach is a simple method with explicit physical meaning and easy to understand and use. The SMAPI is capable of identifying the onset of a drought event, its progression as well as its termination.

The drought (or wet) classification based on the SMAPI was studied prior to the current study. We have calculated the SMAPI values using observed soil moisture collected on the 1st, 11th and 21st of every month from 1981 to 1999 at 10 experimental sites located in different regions of China. Figure 1 shows the frequency distributions of the SMAPI for the 10 sites, as well as their average. It is obvious that the latter pattern can be represented by a Gaussian distribution. The SMAPI can thus be used to compare droughts in different regions. Based on analysis of drought data from the 10 sites, the SMAPI values can be classified into nine categories as shown in Table 1. Our proposed categories are similar to those of Palmer (1965).

\subsection{SMAPI-based identification of drought events}

A drought event can be characterized by its duration, intensity, severity and areal extent. We propose a SMAPIbased drought identification procedure for practical uses in the identification of both grid point and regional drought events, which can be explained as follows. 
Table 1. Soil moisture classifications based on the SMAPI (Soil Moisture Anomaly Percentage Index).

\begin{tabular}{lrr}
\hline Category & SMAPI & $\begin{array}{r}\text { Average } \\
\text { Frequency }\end{array}$ \\
\hline extreme drought & $\leq-50 \%$ & 0.005 \\
severe drought & $-50 \%$ to $-30 \%$ & 0.020 \\
moderate drought & $-30 \%$ to $-15 \%$ & 0.100 \\
mild drought & $-15 \%$ to $-5 \%$ & 0.200 \\
near normal & $-5 \%$ to $5 \%$ & 0.350 \\
slightly wet & $5 \%$ to $15 \%$ & 0.200 \\
moderately wet & $15 \%$ to $30 \%$ & 0.100 \\
very wet & $30 \%$ to $50 \%$ & 0.020 \\
extremely wet & $>50 \%$ & 0.005 \\
\hline
\end{tabular}

For a grid point, we define the drought duration as the number of consecutive days with the SMAPI values below $-5 \%$. The latter is the upper limit of mild droughts in Table 1 . The average of the SMAPI values is called the drought intensity. The drought severity is the product of the drought intensity and the drought duration. In this study, we have used 60 days as the minimum threshold for the drought duration to qualify a drought event at the grid point scale.

The areal extent of droughts is an important feature for identifying large-scale drought events. For a drought study region, we define the daily areal extent as the percentage of the total grid points with the SMAPI values below $-5 \%$. The daily drought intensity of a region refers to the average of the SMAPI values of all grid points covered by that region. Differing from the situation for a grid point, the drought duration of a region is defined as the number of consecutive days with values of the daily areal extent greater than $30 \%$. Similar to a grid point, the drought severity of a region is the product of the daily drought intensity of that region and its drought duration. We also use 60 days as the minimum threshold for the drought duration to qualify a drought event at regional scale.

\subsection{China's nine drought study regions}

China covers a vast area of 9.6 million square kilometers, and is known for its diversified landscapes with plateaus and mountains in the West and lower lands in the East. China's climate varies radically from the North to the South as well as from the West to the East, it crosses five temperature zones. Precipitation in China increases from the Northwest to the Southeast, with significant variations in annual amounts. As a result, China is divided into nine drought study regions by CMWR (1997). Such a division scheme has been adopted in this study to preserve a consistency among regional drought studies, as well as the convention in geographical naming. Figure 2 shows the geographical distribution of these nine drought study regions, which are Xinjiang, Tibet, Northwest, Inner Mongolia, Northeast, North, East, Southwest and

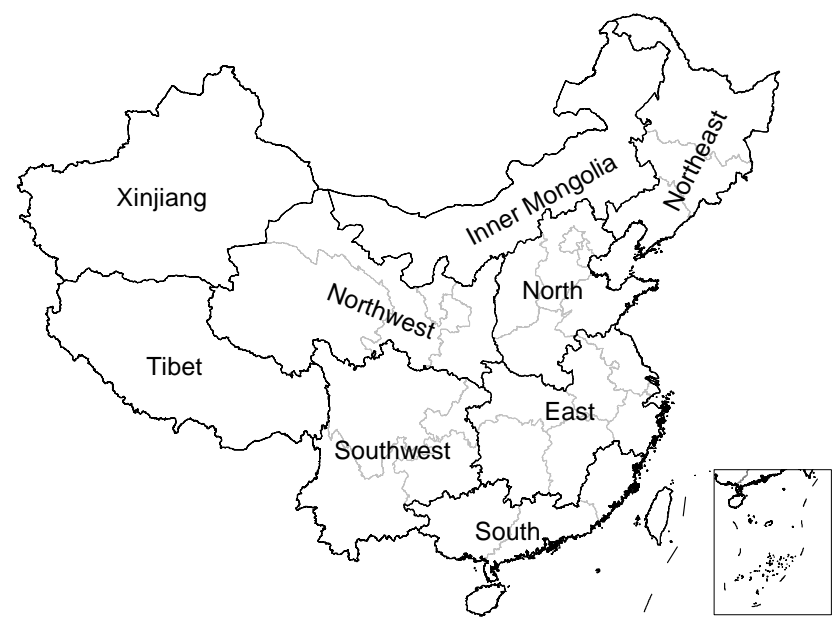

Fig. 2. The geographical distribution of China's nine drought study regions and provinces. The black solid lines delineate the drought study regions, while the gray lines are the boundaries of provinces.

South. Each region includes at least one of the 31 provinces in mainland China.

\section{Result}

\subsection{Annual cycle of soil moisture}

The annual cycle of VIC soil moisture in the top 1-m column is shown in Fig. 3. Each panel of the figure represents the annual time series of spatially-averaged soil moisture, precipitation and evapotranspiration on one of the nine drought study regions in China. The three climatologies are the averages of a 59 -yr period from 1 January 1951 to 31 December 2009. The result shows that the annual variation in soil moisture in these regions differs from each other, varying from high values with a considerable seasonality in the South to very low values having almost no seasonality in Xinjiang. The overall annual variation in soil moisture corresponds well with the observed precipitation gradient crossing China as shown in Fig. 3.

In the nine drought study regions, the annual cycle of soil moisture can be further aggregated into three categories. Xinjiang, Tibet and Northwest form the first category, which can be characterized as regions with low soil moisture values and small seasonality. The second one involves Inner Mongolia, the North and the Northeast, these three regions with low soil moisture values and moderate seasonal variations. In this category, the water storage in the soil column is depleted during spring season while recharged in summer. The maximum value of soil moisture is usually observed in late summer, while the minimum one in early summer. The soil moisture value remains almost constant during autumn and winter. The third category includes the Southwest, the South and the East. High soil moisture values and notable seasonal 

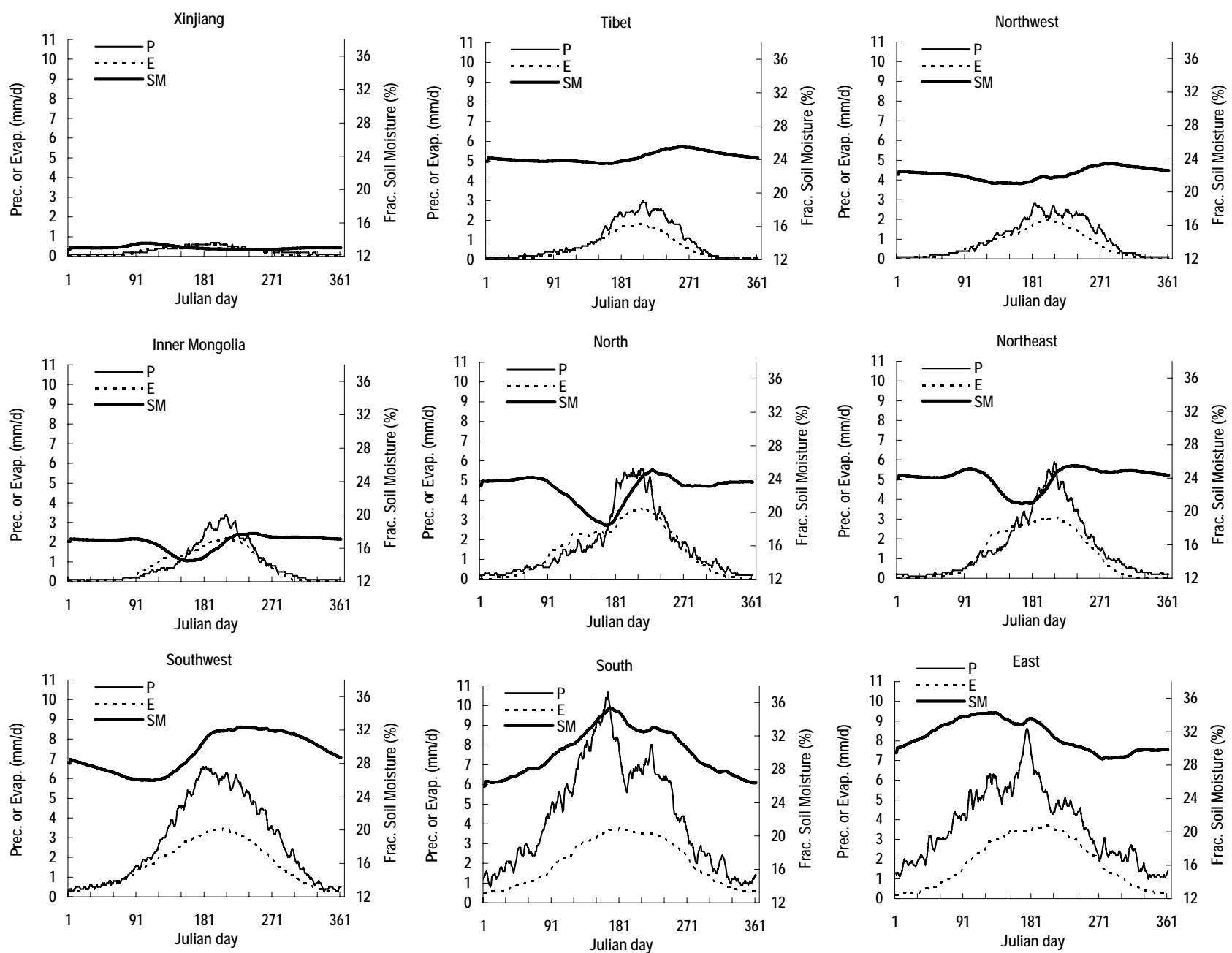

Fig. 3. The annual cycle of VIC soil moisture (SM: thick solid line) for the period 1951-2009 over China's nine drought study regions, as well as the observed precipitation ( $P$ : thin solid line) and the simulated evapotranspiration ( $E$ : dashed line).

variations are the main characteristics observed in those three humid regions. The regions are covered by the East Asian monsoon area that is characterized by a warm and wet summer as well as a cold and dry winter. The soil moisture in the regions can be recharged in the warm season and depleted in the cold season. The annual cycle of soil moisture is largely influenced by the monsoon activities. The occurrences of soil moisture maximum and minimum are different over the three humid regions, which are in August and April over the Southwest, in June and December over the South, and in May and October over the East, respectively. Our proposed three categories are consistent with other drought studies (Zhang et al., 2008a; Zhang, 2009).

\subsection{Identification of regional historical drought events}

We apply the SMAPI-based drought identification procedure to China to identify regional drought events over a 59yr period commencing on 1 January 1951, and ending on
31 December 2009. The SMAPI threshold is set to $-5 \%$ in this study, which is the upper limit of mild droughts in Table 1 . Using the procedure, a total of 325 regional historical drought events can be identified from China's nine drought study regions. These events vary in time and strength. Table 2 summarizes the result of those identified events from the nine regions.

Our study reveals that are the most frequently hit by drought found in the South and the North as shown in the second column of Table 2. Both regions experienced 53 regional drought events from 1951-2009, and then followed by the East with 46 events. Over each region, the top three most severe drought events are given in the last three columns of table after examining the drought severity among the identified events. The beginning and ending dates of a drought event $\left(T_{1} / T_{2}\right)$, the drought duration $(D)$, and the drought areal extent $(A)$ are also listed in the columns. On average, the drought duration in North is about three times longer than 
Table 2. The list of the total regional drought events over China's nine drought study regions indentified by the SMAPI-based procedure during the period 1951 to 2009, with the top three most severe drought events. The regional drought events are sorted according to their severity. The beginning and ending dates $\left(T_{1} / T_{2}\right)$ of a drought event are given, as well as the duration $(D)$ and the drought areal extent $(A)$.

\begin{tabular}{|c|c|c|c|c|c|c|c|c|c|c|}
\hline $\begin{array}{l}\text { Study } \\
\text { regions }\end{array}$ & $\begin{array}{c}\text { Total } \\
\text { drought } \\
\text { events }\end{array}$ & $\begin{array}{l}\text { First ranking } \\
T_{1} / T_{2}\end{array}$ & $D(\mathrm{~d})$ & $A(\%)$ & $\begin{array}{l}\text { Second ranking } \\
T_{1} / T_{2}\end{array}$ & $D(\mathrm{~d})$ & $A(\%)$ & $\begin{array}{l}\text { Third ranking } \\
T_{1} / T_{2}\end{array}$ & $D(\mathrm{~d})$ & $A(\%)$ \\
\hline Xinjiang & 6 & 12 Sep 1956/23 Apr 1957 & 224 & 40.0 & 11 Oct 1997/24 Mar 1998 & 165 & 34.2 & 26 Oct 1955/2 Apr 1956 & 160 & 33.5 \\
\hline Tibet & 25 & 22 Aug 1957/13 Oct 1960 & 1149 & 41.9 & 3 Jul 1994/30 Jun 1996 & 729 & 47.3 & 18 Jun 1952/3 Jul 1954 & 746 & 42.8 \\
\hline Northwest & 26 & 27 May 1952/25 Jan 1954 & 609 & 51.0 & 22 Jun 2006/17 Jun 2007 & 361 & 46.7 & 10 Jul 2002/7 May 2003 & 302 & 48.7 \\
\hline Inner Mongolia & 37 & 14 Jul 1999/10 Jun 2002 & 1063 & 61.0 & 29 Jun 2006/23 Jun 2008 & 726 & 64.1 & 1 Jul 2005/29 Jun 2006 & 364 & 74.2 \\
\hline Northeast & 38 & 24 May 2000/19 Jun 2002 & 757 & 63.5 & 14 Aug 1977/19 Apr 1979 & 614 & 54.5 & 20 Jul 1967/28 Sep 1968 & 437 & 64.0 \\
\hline North & 53 & 27 Aug 1998/22 Oct 2000 & 788 & 75.1 & 29 Jul 1991/3 May 1994 & 1010 & 59.8 & 7 Jul 1980/21 Jun 1982 & 715 & 72.8 \\
\hline East & 46 & 16 Jun 1978/6 May 1979 & 325 & 68.9 & 15 Jul 1966/5 Mar 1967 & 234 & 65.2 & 22 Jul 1992/14 Jan 1993 & 177 & 67.2 \\
\hline Southwest & 41 & 15 Jun 2006/1 Feb 2007 & 232 & 53.6 & 30 Jul 2003/7 Apr 2004 & 253 & 45.3 & 10 Jan 1963/22 Aug 1963 & 225 & 48.3 \\
\hline South & 53 & 20 Sep $1954 / 31$ May 1955 & 254 & 80.7 & 21 Sep 2003/22 Jul 2004 & 306 & 70.2 & 9 Dec 1962/24 Jul 1963 & 228 & 73.2 \\
\hline
\end{tabular}
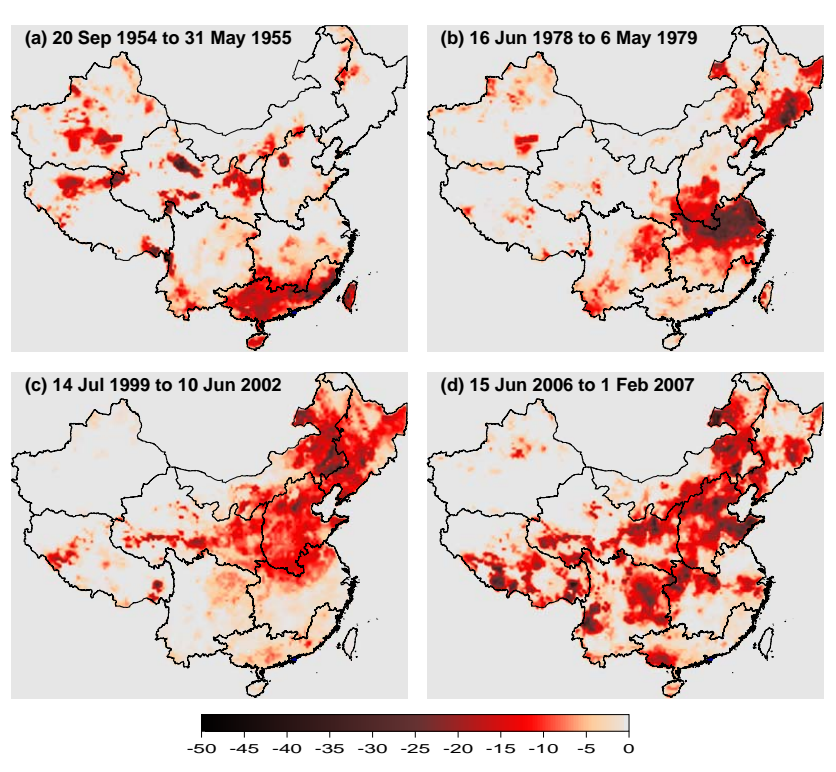

Fig. 4. Four reconstructed most severe drought events together with other drought-affected areas for the same events during the period 1951-2009. (a) South; (b) East; (c) Inner Mongolia; (d) Southwest.

that in the South, although the two regions were hit with the same number of drought events. The region with the least number of drought events is found in Xinjiang, over which only six drought events have been identified from 19512009. The drought duration in Xinjiang is generally shorter than that of other regions.

The analysis has been carried out on the 27 most severe drought events identified from the nine drought study regions. The three drought parameters $T_{1} / T_{2}, D$, and $A$ provided in Table 2 are quantitatively compared with the drought records officially released by the Chinese authorities. The result shows that these identified drought events are in close agreement with the corresponding records most of the time. For example, the first ranking event of the East was from 16 June 1978 to 6 May 1979 . The drought parameters $D$

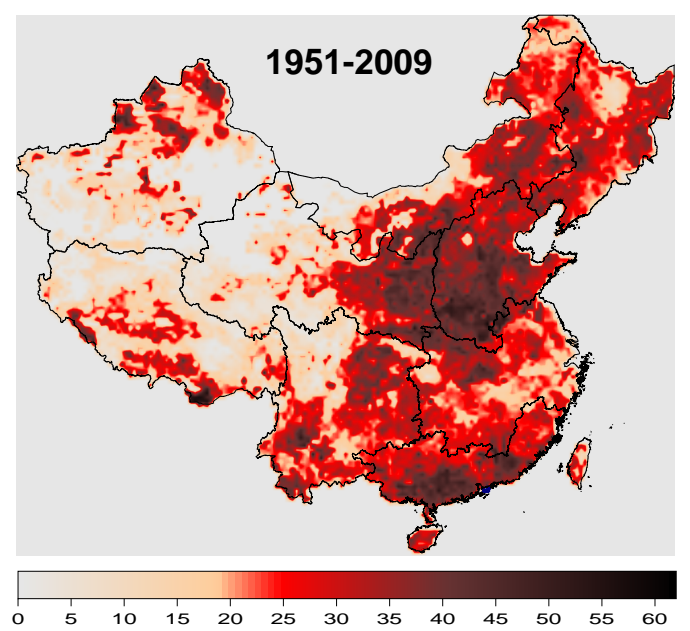

Fig. 5. The geographic distribution of drought occurrence times over China for the period 1951-2009.

(duration) and $A$ (areal extent) are 325 days and $68.9 \%$ respectively as shown in Table 2 . This identified event is well reported in the official document China Historical Drought 1949-2000 (Zhang et al., 2008b), "the severe drought of 1978-1979 in eastern China resulted in a direct loss of 20.1 million tons in grain productions". The second ranking event of Northeast was from 14 August 1977 to 19 April 1979, and having a 614-day duration and $54.5 \%$ areal extent. The corresponding record (Zhang et al., 2008b) showed that a total of 14.6 billion Yuan was lost to the severe drought event of 1977-1979 in northeastern China. In 2000, a series of unprecedented drought events hit China nationwide. These events caused a grain loss of 59.96 million tons, which has made the year 2000 as the most severe drought year since 1949 (Zhang et al., 2008b). The results of the 27 most severe drought events in Table 2 indicate that there were three firstranking drought events involving the most severe drought year 2000. The 757-day long event in the Northeast was from 


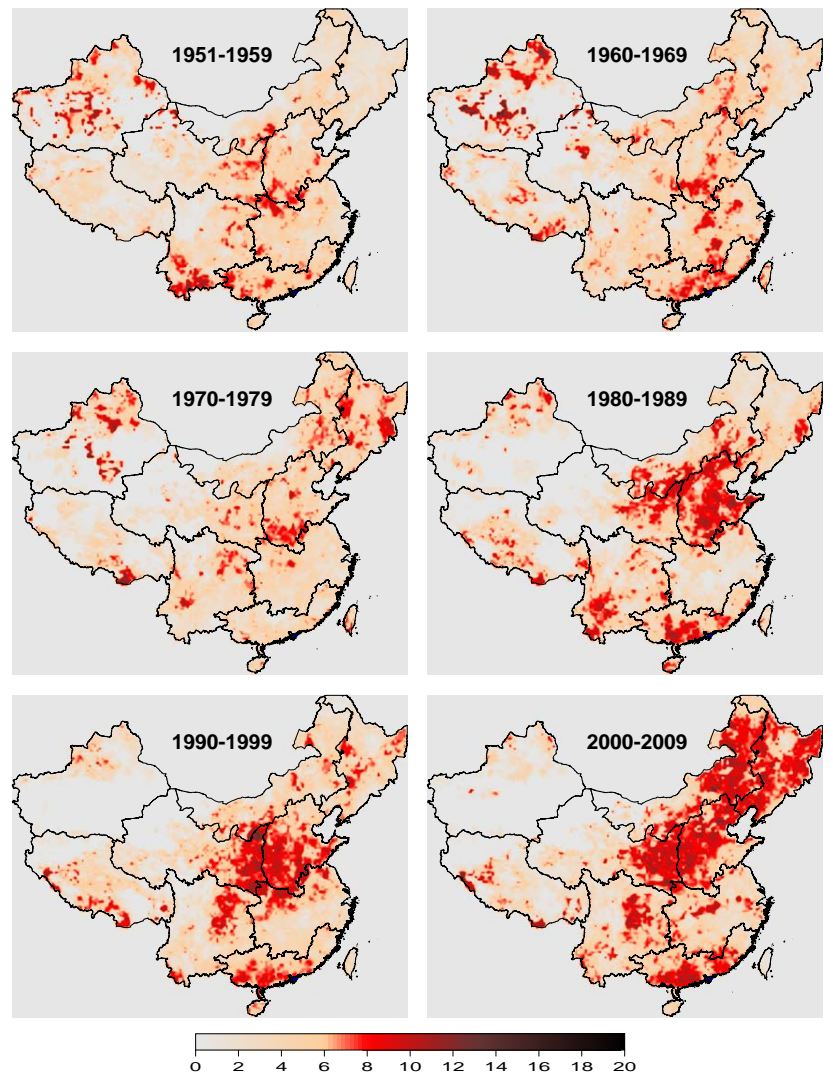

Fig. 6. The geographic distributions of drought occurrence times over China for the six decadal periods, 1951-1959, 1960-1969, 1970-1979, 1980-1989, 1990-1999 and 2000-2009.

24 May 2000 to 19 June 2002. The 788-day long in the North was 27 August 1998 to 22 October 2000; and the 1063-day long in Inner Mongolia was 14 July 1999 to 10 June 2002. These three drought study regions also cover a large portion of China's cultivated lands. Another record-breaking drought event occurred in Chongqing in 2006, which resulted in a severe shortage of drinking water. Chongqing is one of the four municipalities with a population of over 30 million people and is the largest city in western China. The 2006 severe drought had affected more than 21 million people's lives in Chongqing, and two-thirds of its river systems dried up (Hao et al., 2007). This event is also well reconstructed in this study (Table 2), as Chongqing suffered from a 232-day long severe drought event that was first ranking on the Southwest. This event began on 15 June 2006 and ended on 1 February 2007.

\subsection{Spatial extent and variation of droughts in China}

The spatial extent and variation of droughts in China's nine drought study regions are studied. We show in Fig. 4 four reconstructed severe drought events together with other drought-affected areas for the same events to illustrate the drought spatial distribution and extent at both regional and continental scales. All four are ranking first regional events in terms of the drought severity as indicated in Table 2, and they varied in time and strength and occurred on four drought study regions (the South, the East, Inner Mongolia, and the Southwest). Other areas (or grid points) in China with the SMAPI values below $-5 \%$ for the same drought events are also shown on each of the four panels of Fig. 4. This should give us a nationwide complete picture of the drought-affected areas during the episode of four regional drought events, as a large scale severe drought is most likely not an isolated incident. For example, during the occurrence of the 325 day long event in the East (the panel b of Fig. 4), portions of other two drought study regions (the Northeast and the North) were also suffering from droughts during the same 325-day period. This common feature is also observable in the other three panels in Fig. 4.

Over a region, the severity of a drought event is usually not uniformly distributed. Local convergences of a large scale drought event are commonly recognized in many drought studies. This local convergence is also well reconstructed in this study, and many of them are coincide well with the drought records officially released by the authorities. An exception is found in the drought study region (the South) as shown in the panel d of Fig. 4, where the severe drought almost extended to the entire region during the episode of the 254-day long event.

At a grid point scale, the long-term drought occurrence on each of the 10458 VIC grid points in China is examined using the SMAPI-based drought identification procedure over the period from 1 January 1951 to 31 December 2009. For example, a maximum of 62 drought events has been identified from a grid point that happened to be bordered by two drought study regions (the North and the East). Figure 5 shows the geographic distribution of drought occurrences over China from 1951-2009. The drought distribution with different strengths is generally found in most regions of China. However, the drought frequency exhibits a diversified characteristic ranging from low frequency in the West to being very common in the East. The latter poses a serious threat to China as most of the country's socio-economic activities are concentrated in the East. Two regional dry centres are clearly shown in the figure. This discovery is further supported by the analysis of the drought occurrence in the nine drought study regions. As shown in Fig. 5, the first centre is located in the area partially covered by two drought study regions (the North and the Northwest), which extends to the southeastern portion of Inner Mongolia and the southwest part of the Northeast. The second one is found in the central to southern part of the drought study region (the South). The drought occurrence in China East is largely influenced by the location and strength of the western pacific subtropical high as well as the development of the westerly circulation.

The decadal variation in the drought occurrence at each grid point is analyzed. We show in Fig. 6 six geographic 
distributions of drought occurrences over China in the past six decades (1951-1959, 1960-1969, 1970-1979, 19801989, 1990-1999 and 2000-2009). Each panel of the figure represents the drought occurrences in one decade. The nationwide decadal variation of drought occurrences can thus be seen clearly from the six panels of Fig. 6. For example, drought occurrence in China was fairly moderate in the first three decades until the end of the 1970 s, as the grid points with 8 or more accumulated drought events per decade were rare. There were scattered grid points hit by multiple drought events. The large-scale and long-term trend in drought occurrences is found to be insignificant. However, the situation has changed dramatically in last three decades beginning in the early 1080s. There has been a significant increase in the number of grid points with 8 or more accumulated drought events per decade, and they appear to be more organized, structured and regionally concentrated. This regional concentration was clearly evident over the entire drought study region (the North) in the 1980s. Over the next two decades, the regional concentration first developed westward towards the drought study region (the Northwest) in the 1990s, and then further extended northeastward towards the large portion of the drought study region (Inner Mongolia) and almost the entire Northwest in the 2000s. Another smaller center has been growing steadily since the 1960s, and has extended to a large area of the drought study region (the South) in the 2000s. The overall result indicates that the drought situation has been worsening in China, especially in the most socioeconomic concentrated areas, since the 1980s. This finding on drought decadal variations is in good qualitative agreement with observations and many other drought reports released by authorities at different levels in China.

Since most parts of China are located in the East Asian Monsoon area, the monsoon variability is affected by both tropical and mid-latitude circulation systems. The variability is likely to be responsible for the frequent occurrence of extreme drought events in China. In the background of global warming, the climatic characteristics of regional atmospheric water and energy have changed in both time and space, which can result in frequently occurred abnormal circulations and can bring weather extremes such as high temperature and less precipitation. Ma and $\mathrm{Fu}$ (2006) found that the increase of extreme drought events in North China since 1990 were mainly due to precipitation decrease and temperature increase. The increasing water consumption from human activities like population growth, industry and agriculture development, as well as changes of land use and land cover have interfered with the water circulation system in China. All of these factors have increased the vulnerability to drought, thus exacerbating the effects of drought.

\subsection{Trends in the recent 59-yr drought over China's nine drought study regions}

Drought is a regional phenomenon with high spatial and temporal variability. Droughts are recurring aspects of weather and climate extremes. Trends in the recent 59-yr drought over China's nine drought study regions are studied. We show in Fig. 7 the time series of monthly drought areal extents on each drought study region. The trend lines are also shown in the figure. The monthly drought areal extent can be aggregated from the daily drought areal extent over the same study region. As shown in Fig. 7, three drought study regions (Inner Mongolia, the Northeast and the North) exhibited an upward trend, while only one region (Xinjiang) trended downward, and almost no trend can be observed from the rest of the five regions (Tibet, the Northwest, the East, the Southwest and the South). The 59-yr average in monthly drought areal extents has increased by almost $30 \%$ in those three upward regions, while this statistic was only $-17 \%$ for the downward region (Xinjiang) and within $\pm 10 \%$ for the rest of the five regions. It is important to note that there seems to be a sudden upward jump in the monthly areal extent of droughts in Inner Mongolia during the last ten years.

Monthly, annual, inter-annual variations of droughts are clearly evident in most of the nine drought study regions as shown in Fig. 7. The regional difference in these variations is observable. The most active regions with high variability in the monthly areal extent of drought are found to be in the East, the Southwest and the South. For example, the droughtaffected area was less than $10 \%$ on the drought study region the South in September 1979; however, this number was quickly increased to over $95 \%$ in January 1980 in just four months. The frequency of these variations seems to have accelerated in the last two decades.

The decadal trend in the areal extent of droughts has been quantitatively studied over China's nine drought study regions. The decadal areal extent of droughts is calculated based on daily values. We show in Fig. 8 the decadal average of drought area percentages on the nine drought study regions (Xinjiang, Tibet, the Northwest, Inner Mongolia, the Northeast, the North, the East, the Southwest and the South) in the past six decades (1951-1959, 1960-1969, 1970-1979, 1980-1989, 1990-1999 and 2000-2009). On average, up to $30 \%$ of the total area of China is prone to drought, and this finding is consistent with the conclusion from another study based on the calculated Palmer Drought Severity Index (PDSI) using observed precipitation and temperature (Zou et al., 2005). The spatial and temporal variability is observed among regional changes in drought areal extents in the last six decades. Regionally, an upward trend in droughtaffected areas has been detected in three regions (the North, the Northeast and Inner Mongolia) especially during the last $30 \mathrm{yr}$ as shown in Fig. 8. Over the North, more than $50 \%$ of the area has been affected by droughts during the past three decades (1980s, 1990s and 2000s), and this finding is also 

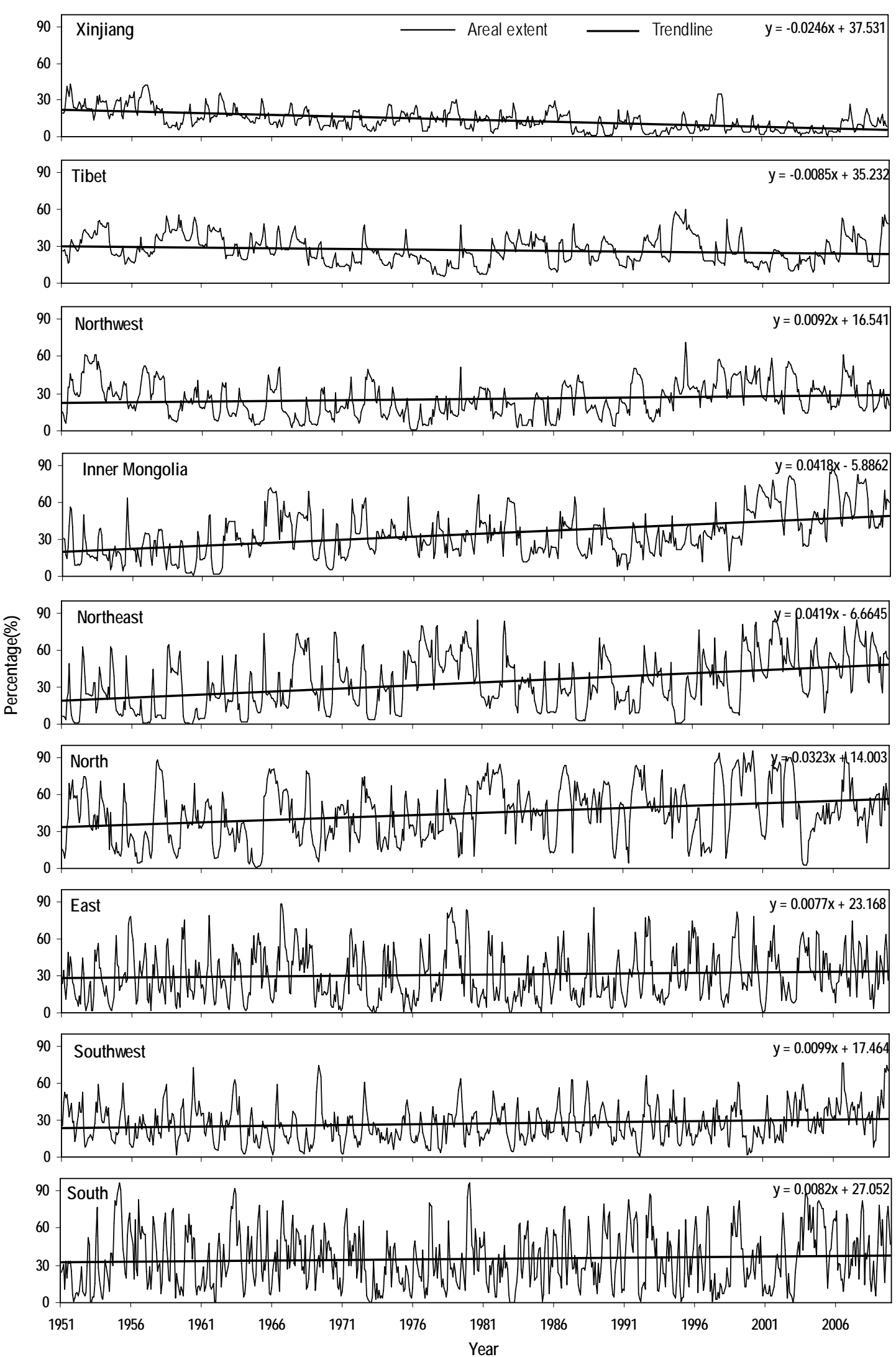

Fig. 7. Time series of the monthly drought areal extents from 1951-2009. The subplots correspond to China's nine drought study regions. 


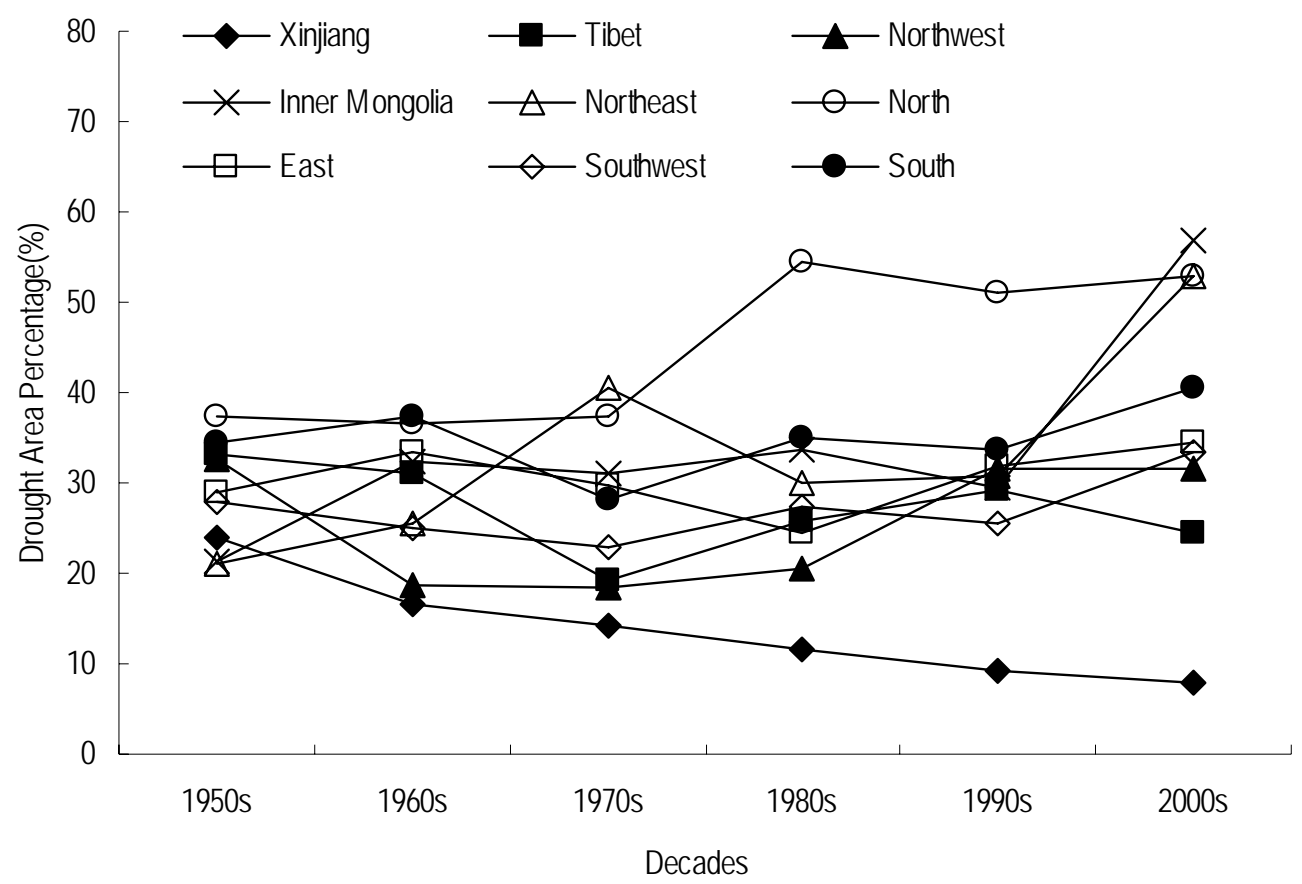

Fig. 8. Decadal average of drought area percentages on the nine drought study regions. The six decades are 1950s (1951-1959), 1960s (1960-1969), 1970s (1970-1979), 1980s (1980-1989), 1990s (1990-1999) and 2000s (2000-2009).

in good agreement with other two studies (Wang and Zhai, 2003; Zou et al., 2005). For example, Wang and Zhai (2003) revealed an expanding trend of drought areas in major northern agricultural areas in the last fifty years using the China-Z index, while Zou et al. (2005) obtained a similar trend using the PDSI index, and our study confirms these observations. However, the decadal variability of droughts has been weak in the rest of the five regions (the South, the Southwest, the East, the Northwest, and Tibet). Xinjiang has even been showing steadily wetter since the 1950 s, which is also reported by Ma and $\mathrm{Fu}$ (2003).

\section{Conclusions}

We have used the VIC land surface macroscale hydrology model to reconstruct China's daily soil moisture values from 1 January 1951 to 31 December 2009, at a spatial resolution of $30 \mathrm{~km} \times 30 \mathrm{~km}$. VIC is applied over a grid of 10458 points, and is driven by observed daily maximum and minimum air temperature and precipitation from 624 long-term meteorological stations. VIC performs well over both calibration and validation catchments especially in humid and semi-humid regions, and detailed VIC calibration and validation are found in Wu et al. (2007). This newly-completed multiyear VIC simulation has extended the simulation period from previous thirty-five years (1971-2005; Wu et al., 2003) to current fifty-nine years (1951-2009), and can thus provide us with a 59-yr soil moisture dataset for this study.
The VIC soil moisture is used to calculate the Soil Moisture Anomaly Percentage Index (SMAPI). The latter can be used as a measure of the severity of agricultural drought on a global basis. We developed a SMAPI-based drought identification procedure for practical uses in the identification of both grid point and regional drought events. As a result, a total of 325 regional drought events varying in time and strength have been identified from China's nine drought study regions (Xinjiang, Tibet, the Northwest, Inner Mongolia, the Northeast, the North, the East, the Southwest and the South). The result shows that the severe drought events of 1978, 2000 and 2006 are well reconstructed, which indicates that the SMAPI is capable of indentifying the onset of a drought event, its progression, as well as its termination.

The identified drought events have been assessed quantitatively at different spatial and temporal scales. Teh results show that on average, up to $30 \%$ of the total area of China is prone to drought. The drought frequency exhibits a diversified characteristic ranging from low frequency in the West to very common in the East. Regionally, an upward trend in drought-affected areas has been detected in three regions (Inner Mongolia, the Northeast and the North) from 19512009. The 59-yr average in monthly drought areal extents has increased by almost $30 \%$ in the three upward regions, while this statistic was only $-17 \%$ for the downward region (Xinjiang) and within $\pm 10 \%$ for the rest of the five regions. It is important to note that there seems to be a sudden upward jump in the monthly areal extent of droughts in Inner Mongolia during the last ten years. 
The upward drought trends are likely the result of interactions of climate change and human activities. Atmospheric circulation anomaly caused by global warming leads to the decrease of areal precipitation and the increase of surface temperature, which can cause frequently occurring drought events. Many human activities like population expansion, urbanization and industrial development can lead to an increase in water demand. The destruction of surface land covers resulting from irrational utilization of land aggravates the occurrence and development of droughts. The drought trends directly influence the amount of water available for agricultural productivity, slowing down grain production and reducing crop yields. On the other hand, soil moisture deficits induced by droughts will exacerbate land desertification and the expansion of desertification, as well as enlarging the existing problem of land salinization in northern areas. In addition, frequently occurringd droughts will caused river-lake water levels to decline, lake surface areas to reduce, and even dry up, having serious effects on the ecological environment. Therefore, further analyzing drought causes and mechanisms and improving the monitoring and prediction ability of droughts would be the key direction for future drought research.

Two regional dry centres have been discovered in China as the result of a combined analysis on the occurrence of drought events from both grid points and drought study regions. The first centre is located in the area partially covered by two drought study regions (the North and the Northwest). The centre extends to the southeastern portion of Inner Mongolia and the southwest part of the Northeast. The location of the second centre is found on the central to southern portion of the South. Our study demonstrates the applicability and the value of using modeled soil moisture for reconstructing drought histories, and the SMAPI is useful to analyze drought at different spatial and temporal scales. The SMAPIbased methodology would be applicable for real time drought monitoring and forecasting with meteorological forecasts being provided, as our VIC soil moisture simulation emphasizes on the idea of maintaining consistency between realtime and long-term soil moisture simulations. Based on the current study, the following recommendations are generally intended for future VIC studies in China. First, it would be desirable to have additional observed meteorological variables, which will help to reduce the uncertainty in model inputs. Second, we will increase the number of VIC calibration and validation catchments, in particular those with a large catchment size. Third, we will improve the form of the spatial probability function currently used in VIC to better represent the sub-grid variability in soil moisture storage capacity.

Acknowledgements. This work is supported by the National Natural Science Foundation of China (grant No. 41001012), the National Basic Research Program of China (973 Program) (grant No. 2010CB428405), the Special Public Sector Research Program of Ministry of Water Resources (Grant No. 200701039) and the
Fundamental Research Funds for the Central Universities (Grant No. 2009B00114). We are very grateful to three anonymous referees for their constructive comments and suggestions that have improved the paper immensely.

Edited by: H. Cloke

\section{References}

Albergel, C., Calvet, J.-C., de Rosnay, P., Balsamo, G., Wagner, W., Hasenauer, S., Naeimi, V., Martin, E., Bazile, E., Bouyssel, F., and Mahfouf, J.-F.: Cross-evaluation of modelled and remotely sensed surface soil moisture with in situ data in southwestern France, Hydrol. Earth Syst. Sci., 14, 2177-2191, doi:10.5194/hess-14-2177-2010, 2010.

Andreadis, K. M., Clark, E. A., Wood, A. W., Hamlet, A. F, and Lettenmaier, D. P.: Twentieth-century century drought in the conterminous United States, J. Hydrometeorol., 6, 985-1001, 2005.

Bergman, K. H., Sabol, P., and Miskus, D.: Experimental indices for monitoring global drought conditions, in: Proc. 13th Annual Climate Diagnostics Workshop, Cambridge, MA, US Dept. of Commerce, 190-197, 1988.

Bordi, I., Fraedrich, K., and Sutera, A.: Observed drought and wetness trends in Europe: an update, Hydrol. Earth Syst. Sci., 13, 1519-1530, doi:10.5194/hess-13-1519-2009, 2009.

Dai, A. G., Trenberth, K. E., and Qian, T. T.: A global dataset of palmer drought severity index for 1870-2002: relationship with soil moisture and effects of surface warming, J. Hydrometeorol., 5, 1117-1130, 2004.

Dümenil, L. and Todini, E.: A rainfall-runoff scheme for use in the Hamburg climate model, in: Advances in Theoretical Hydrology, a Tribute to James Dooge, edited by: O'Kane, J., European Geophysical Society Series in Hydrological Sciences, 1, Elsevier, Amsterdam, 129-157, 1992.

Gray, D. M.: Handbook on the Principles of Hydrology, Water Information Center, NY, 1970.

Habets, F., Noilhan, J., Golaz, C., Goutorbe, J. P., Lacarrère, P., Leblois, E., Ledoux, E., Martin, E., Ottlé, C., and VidalMadjar, D.: The ISBA surface scheme in a macroscale hydrological model applied to the Hapex-Mobilhy area Part 1: Model and database, J. Hydrol., 217, 75-96, 1999.

Hansen, M. C., Defries, R. S., Townshend, J. R. G., and Sohlberg, R.: Global land cover classification at $1 \mathrm{~km}$ spatial resolution using a classification tree approach, Int. J. Remote Sensing, 21, 1331-1364, 2000

Hao, Z. X., Ge, Q. S., Zhen, J. Y., and Li, Y. Q.: 2006 extreme drought event of Chongqing, Geogr. Res., 26, 828-834, 2007.

Heim, R. R.: Drought indices: a review, in: Drought: A Global Assessment, edited by: Wilhite, D. A., Routledge, 159-167, 2000.

Juglea, S., Kerr, Y., Mialon, A., Lopez-Baeza, E., Braithwaite, D., and Hsu, K.: Soil moisture modelling of a SMOS pixel: interest of using the PERSIANN database over the Valencia Anchor Station, Hydrol. Earth Syst. Sci., 14, 1509-1525, doi:10.5194/hess14-1509-2010, 2010.

Keyantash, J. and Dracup, A.: The quantification of drought: an evaluation of drought indices, B. Am. Meteorol. Soc., 23, 11671180, 2002.

Liang, X., Lettenmaier, D. P., Wood, E. F., and Burges, S. J.: A simple hydrologically based model of land-surface water and energy 
fluxes for general circulation models, J. Geophys. Res., 99(D7), 14415-14428, 1994.

Liang, X., Wood, E. F., and Lettenmaier, D. P.: Surface soil moisture parameterization of the VIC-2L model: evaluation and modification, Global Planet. Change, 13, 195-206, 1996.

Lievens, H., Verhoest, N. E. C., De Keyser, E., Vernieuwe, H., Matgen, P., Álvarez-Mozos, J., and De Baets, B.: Effective roughness modelling as a tool for soil moisture retrieval from C- and L-band SAR, Hydrol. Earth Syst. Sci., 15, 151-162, doi:10.5194/hess-15-151-2011, 2011.

Loew, A. and Schlenz, F.: A dynamic approach for evaluating coarse scale satellite soil moisture products, Hydrol. Earth Syst. Sci., 15, 75-90, doi:10.5194/hess-15-75-2011, 2011.

Lobmeyr, M., Lohmann, D., and Ruhe, C.: An application of a large scale conceptual hydrological model over the Elbe region, Hydrol. Earth Syst. Sci., 3, 363-374, doi:10.5194/hess-3-3631999, 1999.

Ma, Z. G. and Fu, C. B.: Interannual characteristics of the surface hydrological variables over the arid and semi-arid areas of Northern China, Global Planet. Change, 37, 189-200, doi:10.1016/S0921-8181(02)00203-5, 2003.

$\mathrm{Ma}, \mathrm{Z}$. G. and Fu, C. B.: Some evidence of drying trend over northern China from 1951 to 2004, Chinese Sci. Bull. , 51, 2913-2925, 2006.

Ma, Z. G. and Ren, X. B.: Drying Trend over China from 1951 to 2006, Adv. Clim. Change Res., 3(4), 195-201, 2007.

McKee, T. B. N., Doesken, J., and Kleist, J.: The relationship of drought frecuency and duration to time scales, Eight Conf. on Applied Climatology, Anaheim, CA, Am. Meteorol. Soc., 179184, 1993.

Mo, K. C.: Model-based drought indices over the United States, J. Hydrometeorol., 9, 1212-1230, 2008.

Narasimhan, B. and Srinivasan, R.: Development and evaluation of soil moisture deficit index (SMDI) and evapotranspiration deficit index (ETDI) for agricultural drought monitoring, Agr. Forest Meteorol., 133, 69-88, 2005.

Nijssen, B., Schnur, R., and Lettenmaier, D. P.: Global retrospective estimation of soil moisture using the variable infiltration capacity land surface model, 1980-93, J. Climate, 14, 1790-1808, 2001.

Office of State Flood Control and Drought Relief Headquarters and Nanjing Institute of Hydrology and Water Resources, Ministry of Water Resources, China (Eds.): China flood and drought disaster, China WaterPower Press, Beijing, 569 pp., 1997.

Palmer, W. C.: Meteorological drought, Weather Bureau, Research Paper No. 45, US Dept. of Commerce, Washington, DC, 58 pp., 1965.

Palmer, W. C.: Keeping track of crop moisture conditions, nationwide: the new crop moisture index, Weatherwise, 21, 156-161, 1968.

Raziei, T., Bordi, I., and Pereira, L. S.: A precipitation-based regionalization for Western Iran and regional drought variability, Hydrol. Earth Syst. Sci., 12, 1309-1321, doi:10.5194/hess-121309-2008, 2008.

Reynolds, C. A., Jackson, T. J., and Rawls, W. J.: Estimating soil water-holding capacities by linking the Food and Agriculture Organization soil map of the world with global pedon databases and continuous pedotransfer functions, Water Resour. Res., 36, 3653-3662, 2000.

Richard, R. and Heim, J. R.: A review of twentieth century drought index used in the United States, B. Am. Meteorol. Soc., 83, 1149-1165, 2002.

Sheffield, J., Goteti, G., Wen, F., and Wood, E. F.: A simulated soil moisture based drought analysis for the United States, J. Geophys. Res., 109, D24108, doi:10.1029/2004JD005182, 2004.

Stephen, H., Ahmad, S., Piechota, T. C., and Tang, C.: Relating surface backscatter response from TRMM precipitation radar to soil moisture: results over a semi-arid region, Hydrol. Earth Syst. Sci., 14, 193-204, doi:10.5194/hess-14-193-2010, 2010.

te Linde, A. H., Aerts, J. C. J. H., Hurkmans, R. T. W. L., and Eberle, M.: Comparing model performance of two rainfallrunoff models in the Rhine basin using different atmospheric forcing data sets, Hydrol. Earth Syst. Sci., 12, 943-957, doi:10.5194/hess-12-943-2008, 2008.

Verseghy, D. L.: CLASS A Canadian land surface scheme for GCMS, I. Soil model, Int. J. Climatol., 11, 111-133, 1991.

Verseghy, D. L., McFarlane, N. A., and Lazare, M.: CLASS A Canadian land surface scheme for GCMS, II. Vegetation model and coupled runs, Int. J. Climatol., 13, 347-370, 1993.

Vicente-Serrano, S. M. and López-Moreno, J. I.: Hydrological response to different time scales of climatological drought: an evaluation of the Standardized Precipitation Index in a mountainous Mediterranean basin, Hydrol. Earth Syst. Sci., 9, 523-533, doi:10.5194/hess-9-523-2005, 2005.

Wang, Z. W. and Zhai, P. M.: Climate change in drought over Northern China during 1950-2000, Acta Geogr. Sin., supplement, 58, 61-68, 2003.

Wen, K., Jin, G. S., and Li, D. J.: A mathematical model for catchment runoff calculation, J. Hydraul. Eng., 13, 1-12, 1982.

Wen, L., Wu, Z. Y., Lu, G. H., Lin, C. A., Zhang, J. Y., and Yang, Y.: Analysis and improvement of runoff generation in the land surface scheme CLASS and comparison with field measurements from China, J. Hydrol., 345, 1-15, 2007.

Wen, L., Lin, C. A., Wu, Z. Y., Lu, G. H., Pomeroy, J., Zhu, Y. F.: Reconstructing sixty year (1950-2009) daily soil moisture over the Canadian Prairies using the Variable Infiltration Capacity model, Canadian Water Resour. J., 83-102, 2011.

WMO: Drought and Agriculture, WMO Tech, Note 138, Geneva, Switzerland, 127 pp., 1975.

Wu, Z. Y., Lu, G. H., Wen, L., Lin, C. A., Zhang, J. Y., and Yang, Y.: Thirty-five year (1971-2005) simulation of daily soil moisture using the variable infiltration capacity model over China, Atmos. Ocean, 45, 37-45, 2007.

Zhai, J. Q., Su, B. D., and Krysanova, V.: Spatial variation and trends in PDSI and SPI indices and their relation to streamflow in 10 large regions of China, J. Climate, 23, 649-663, doi:10.1175/2009JCLI2968.1, 2010.

Zhang, S. F., Su, Y. S., and Song, D. D.: China historical drought 1949-2000, Hohai University Press, Nanjing, 680 pp., 2008a.

Zhang, W. Y.: On China drought disaster and mitigation measures, disaster reduction in China, 1, 47-49, 2003.

Zhang, W. J., Zhou, T. J., and Yu, R. C.: Spatial distribution and temporal variation of soil moisture over China - Part I: Multidata intercomparison, Chinese J. Atmos. Sci., 32(3), 581-597, 2008 b.

Zhang, X. Y.: Analysis and assesment of soil moisture in China based on the situ observation data, Dissertation for the Master Degree, China University of Geosciences, Beijing, 77 pp., 2009. 
Zhao, R. J., Zhang, Y. L., Fang, L. R., Liu, X. R., and Zhang, Q. S.: The Xinanjiang model, in: Hydrological Forecasting Proceedings Oxford Symposium, IASH 129, 351-356, 1980.

Zou, X. K., Zhai, P. M., and Zhang, Q.: Variations in droughts over China: 1951-2003, Geophys. Res. Lett., 32, L04707, doi:10.1029/2004GL021853, 2005.
Zuo, Z. Y. and Zhang, R. H.: Temporal and spatial variation of soil moisture in spring over Eastern China, Sci. China Ser. D, 11, 1428-1437, 2008. 